\title{
DESAIN MODEL RELASIONAL DATA TARGET COSTING SYSTEM
}

\author{
M. Mastotok Illah \\ Sekolah Tinggi Ilmu Ekonomi Kertanegara Malang \\ totok_illah@stiekma.ac.id
}

\begin{abstract}
Abstract: This study aims to design an information system that can support research implementation of target costing system with Data Analysis Program, to design the Program Data analysis in research, analyse the effectiveness of the program to be used and evaluate the weakness and superiority of the program will come. In this study the authors use the questionnaire distribution tool Design Model Relational Data Target Costing System, for the purpose of research can be achieved more accurately. In designing the design of Target Costing questionnaire to the built system shows that the Target Costing questionnaire that has been designed is useful to provide an information system that can generate output (output) and input (entry, edit, inquiry, add record), based on the input query According to the required researcher needs related to the target costing. Access program as a tool to design, create tables, create forms and create reports. To display accurate results, then by designing the Target Costing questionnaire, can display data that produces graphs, reports, queries or filter data with Filter by Form to facilitate the search data in accordance with the needs of researchers.
\end{abstract}

Keywords: Relational Data Model, Target Costing System

\section{PENDAHULUAN}

Menganalisis implementasi target costing system di Indonesia. Riset tentang implementasi target costing system adalah sangat penting untuk dilakukan di Indonesia, karena target costing dapat digunakan untuk menentukan desain produk yang profitable di awal siklus hidup produk. Target Costing System merupakan suatu pendekatan baru yang dapat membantu untuk menciptakan produk-produk yang berkualitas (Institute of Management Accountants, 1998).

Dalam penelitian ini perlu didukung dengan data-data yang akurat. Data-data kuesioner yang dikumpulkan tidak harus berupa angka-angka saja, namun bisa juga dalam tekstual atau dalam bentuk parameter lainnya. Data-data ini ada yang bersifat nominal, ordinal, interval, dan rasio, terutama data-data yang bersifat kualitatif seperti ucapan-ucapan, tanggapantanggapan, tulisan-tulisan dan lain sebagainya yang dikumpulkan dan di analisa untuk meningkatkan suatu pemahaman tentang kejadian atau fenomena yang menjadi minat penelitian atau biasa disebut juga sebagai point of interest. Pada akhirnya data inilah yang akan diolah dan di desain sebagai kuesioner sesuai dengan tahapan penelitian yang ada.

Dalam melakukan penelitian salah satu hal yang penting ialah membuat desain eksperimental yang merupakan suatu metodolgi yang tepat untuk membantu penelitian yang dilakukan dalam bidang ilmu komputer. Selain itu ada pendekatan ilmiah untuk memunculkan pengetahuan baru.

Desain kuesioner dalam penelitian ini untuk mempermudah dalam pengisian kuesioner dalam berbagai jenis perusahaan industry antara lain industri mobil, elektronik, peralatan rumah tangga maupun barang konsumen yang ada di perusahaanperusahaan di Indonesia, sehingga dari segi output bisa menghasilkan hasil print out, 
rekapitulasi kuesioner maupun grafik kuesioner yang telah dilakukan dari hasil penyebaran kuesioner target costing system kepada perusahaan-perusahaan di Indonesia. Tanpa menggunakan program desain kuesioner seorang peneliti tidak akan dapat melihat berapa jumlah kuesioner yang telah yang telah dikirimkan dan kembali kemudian rekapitulasi hasil kuesioner dari berbagai jenis industri yang telah dilakukan oleh para peneliti. Manfaat desain kuesioner penelitian akan dirasakan oleh semua pihak yang terlibat dalam proses penelitian, karena dapat digunakan sebagai pedoman dalam melakukan proses penelitian.

Selain itu, agar sebuah penelitian memiliki batasan-batasan dan dapat disusun secara terstruktur dan terkonsep dengan baik, maka diperlukan sebuah metode penelitian mengingat betapa pentingnya desain dan metode penelitian. Salah satu alat desain kuesioner sistem informasi pemetaan riset akuntansi dengan pendekatan target costing system adalah sistem berbasis komputer dengan menggunakan Microsoft Acces untuk membantu mempermudah dalam pengolahan data kuesioner yang selama ini belum ada.

Tujuan penelitian ini adalah : untuk mendesain sistem informasi yang dapat mendukung riset-riset implementasi target costing sisem dengan Program Analisis Data, untuk merancang Program Analisis data dalam penelitian, menganalisis efektifitas program yang akan digunakan, dan mengevaluasi kelemahan dan keunggulan program akan datang.

\section{TINJAUAN PUSTAKA}

\section{Konsep Dasar Informasi}

"Informasi adalah data yang telah diolah menjadi bentuk yang memiliki arti bagi si penerima dan bermanfaat bagi pengambilan keputusan saat ini atau mendatang " (Cleod, 2002). Secara umum informasi dapat didefinisikan sebagai hasil dari pengolahan data dalam suatu bentuk yang lebih berguna dan lebih berarti bagi penerimanya yang menggambarkan suatu kejadian-kejadian yang nyata digunakan untuk pengambilan keputusan.

Sumber dari informasi adalah data. Data adalah kenyataan yang menggambarkan suatu kejadian-kejadian dan kesatuan nyata. Kejadian-kejadian adalah sesuatu yang terjadi pada saat tertentu. Di dalam dunia bisnis, kejadiankejadian yang sering terjadi adalah transaksi perubahan dari suatu nilai yang disebut transaksi. Kesatuan nyata adalah berupa suatu obyek nyata seperti tempat. Benda, dan orang yang betul-betul ada dan terjadi.

Data yang diolah melalui suatu model menjadi informasi, penerima kemudian menerima informasi tersebut, membuat suatu keputusan dan melakukan tindakan, yang berarti menghasilkan suatu tindakan yang lain yang akan membuat sejumlah data kembali. Data tersebut akan ditangkap sabagai input, diproses kembali lewat suatu model dan seterusnya membentuk suatu siklus.

\section{Kualitas Informasi}

Menurut Jogiyanto (2005:10) Kualitas dari suatu informasi (Quality of Information) tergantung dari tiga hal, yaitu informasi harus akurat (Accurate), tepat pada waktunya (Timeliness), dan relevan (Relevance). Menurut Tata Sutabri (2005:35) Kualitas suatu informasi tergantung dari tiga hal yaitu, informasi harus akurat (Accurate), tepat waktu (Timeliness), dan relevan (Relevance).

\section{Sistem Informasi}

Untuk memahami pengertian sistem informasi, harus dilihat keterkaitan antara data dan informasi sebagai entitas penting pembentuk sistem informasi. Data merupakan nilai, keadaan, atau sifat yang berdiri sendiri lepas dari konteks apapun. Sementara informasi adalah data yang telah diolah menjadi sebuah bentuk yang berarti bagi penerimanya dan bermanfaat dalam pengambilan keputusan saat ini atau mendatang (Davis, 1995). Mc Leod (1995) mengatakan bahwa informasi adalah data 
yang telah diproses, atau data yang memiliki arti.

Sistem Informasi Manajemen (SIM) dapat didefinisikan sebagai suatu alat untuk menyajikan informasi dengan cara sedemikian rupa sehingga bermanfaat bagi penerimanya (Kertahadi, 1995). Tujuannya adalah untuk menyajikan informasi guna pengambilan keputusan pada perencanaan, pemrakarsaan, pengorganisasian, pengendalian kegiatan operasi subsistem suatu perusahaan, dan menyajikan sinergi organisasi pada proses (Murdick dan Ross, 1993).

\section{Komponen Sistem Informasi}

Sistem informasi terdiri dari sekelompok komponen yang saling berhubungan, bekerja sama untuk mencapai tujuan bersama dengan menerima input serta menghasilkan output dalam proses transformasi yang teratur (Ladjamudin, 2005).

Kerangka konsep berbagai komponen dan aktivitas sistem informasi dapat dilihat pada gambar di bawah ini :

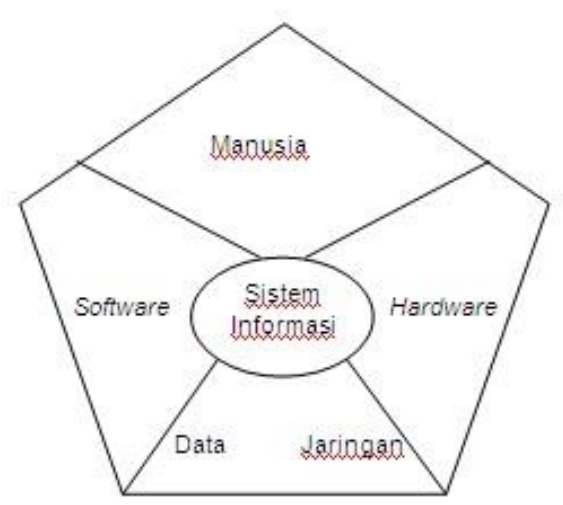

\section{Gambar 1 Kerangka Konsep}

Berdasarkan gambar di atas, komponenkomponen sistem informasi terdiri dari:

\section{Manusia}

Manusia diperlukan dalam operasi sistem informasi. Sumber daya manusia ini meliputi pemakai akhir dan pakar sistem. Pemakai akhir adalah orang yang menggunakan informasi yang dihasilkan sistem informasi, misalnya pelanggan, pemasok, teknisi, mahasiswa, dosen dan orang-orang yang berkepentingan. Sedangkan pakar sistem informasi adalah orang yang mengembangkan dan mengoperasikan sistem informasi, misalnya system analyst, developer, operator sistem dan staf administrasi lainnya (Mulyanto, 2009).

2. Hardware

Sumber daya hardware adalah semua peralatan yang digunakan dalam memproses informasi, misalnya komputer dan periferalnya, lembar kertas, disk magnetic atau optik dan flash disk (Mulyanto, 2009).

3. Software

Software merupakan sekumpulan perintah/fungsi yang ditulis dengan aturan tertentu untuk memerintahkan komputer agar melaksanakan sesuatu (Ladjamudin, 2005).

4. Data

Data merupakan dasar sumber daya organisasi yang diperlukan untuk memproses informasi. Data dapat berbentuk teks, gambar, audio maupun video. Sumber daya informasi umumnya diatur, disimpan dan diakses oleh berbagai pengelolaan sumber daya data ke dalam database dan dasar pengetahuan (Lajamudin, 2005).

5. Jaringan

Sumber daya jaringan merupakan media komunikasi yang menghubungkan komputer, pemroses komunikasi dan peralatan lainnya dengan kendali software komunikasi. Jaringan dapat berupa kabel, satelit, seluler dan pendukung jaringan seperti modem, software pengendali serta prosesor antar jaringan (Ladjamudin, 2005).

Keseluruhan komponen sistem informasi tersebut saling terkait satu sama lain dalam sistem informasi. Sistem informasi dibangun menggunakan teknologi komunikasi dan informasi yaitu hardware, software dan jaringan. Ketiga komponen tersebut dipakai untuk mengolah data yang diperoleh untuk menghasilkan informasi yang lebih bermanfaat. Keseluruhan proses 
pengolahan informasi tidak lepas dari komponen manusia. Manusia adalah komponen penting sistem informasi karena sistem informasi adalah benda yang tidak bermanfaat bila tidak digunakan oleh manusia.

\section{Aktivitas Sistem Informasi}

Stair (1992) menjelaskan bahwa sistem informasi berbasis komputer (CBIS) dalam suatu organisasi terdiri dari komponen-komponen berikut :

a. Perangkat keras, yaitu perangkat keras komponen untuk melengkapi kegiatan memasukkan data, memproses data, dan keluaran data.

b. Perangkat lunak, yaitu program dan instruksi yang diberikan ke komputer.

c. Database, yaitu kumpulan data dan informasi yang diorganisasikan sedemikian rupa sehingga mudah diakses pengguna sistem informasi.

d. Telekomunikasi, yaitu komunikasi yang menghubungkan antara pengguna sistem dengan sistem komputer secara bersama-sama ke dalam suatu jaringan kerja yang efektif.

e. Manusia, yaitu personel dari sistem informasi, meliputi manajer, analis, programmer, dan operator, serta yang bertanggung jawab terhadap perawatan sistem.

f. Prosedur, yakni tata cara yang meliputi strategi, kebijakan, metode, dan peraturan-peraturan dalam menggunakan sistem informasi berbasis komputer.

Sementara Burch dan Grudnitski (1986) berpendapat, sistem informasi yang terdiri dari komponen-komponen di atas disebut dengan istilah blok bangunan (building block), yaitu blok masukan (input block), blok model (model block), blok keluaran (output block), blok teknologi (technology block), dan blok kendali (control block). Sebagai suatu sistem, keenam blok tersebut masing-masing saling berinteraksi satu dengan yang lainnya membentuk satu kesatuan untuk mencapai sasarannya.
Sementara, menurut pendapat Davis (1995), sistem informasi manajemen terdiri dari elemen-elemen berikut :

1. Perangkat keras komputer (hardware)

2. Perangkat lunak (software), yang terdiri dari perangkat lunak sistem umum, perangkat lunak terapan, dan program aplikasi.

3. Database

4. Prosedur

5. Petugas operasional.

\section{Sistem Pendukung Keputusan}

Pengambilan keputusan merupakan proses pemilihan alternatif tindakan untuk mencapai tujuan atau sasaran tertentu. Pengambilan keputusan dilakukan dengan pendekatan sistematis terhadap permasalahan melalui proses pengumpulan data menjadi informasi serta ditambah dengan faktor - faktor yang perlu dipertimbangkan dalam pengambilan keputusan.

Menurut Simon (Kadarsah, 2002:1516), tahap - tahap yang harus dilalui dalam proses pengambilan keputusan sebagai berikut :

1. Tahap Pemahaman (Inteligence Phase) Tahap ini merupakan proses penelusuran dan pendeteksian dari lingkup problematika serta proses pengenalan masalah. Data masukan diperoleh, diproses, dan diuji dalam rangka mengidentifikasikan masalah.

2. Tahap Perancangan (Design Phase)

Tahap ini merupakan proses pengembangan dan pencarian alternatif tindakan / solusi yang dapat diambil. Tersebut merupakan representasi kejadian nyata yang disederhanakan, sehingga diperlukan proses validasi dan vertifikasi untuk mengetahui keakuratan model dalam meneliti masalah yang ada.

3. Tahap Pemilihan (Choice Phase)

Tahap ini dilakukan pemilihan terhadap di antara berbagai alternatif solusi yang dimunculkan pada tahap perencanaan agar ditentukan / dengan 
memperhatikan kriteria - kriteria berdasarkan tujuan yang akan dicapai.

4. Tahap Impelementasi (Implementation Phase)

Tahap ini dilakukan penerapan terhadap rancangan sistem yang telah dibuat pada tahap perancangan serta pelaksanaan alternatif tindakan yang telah dipilih pada tahap pemilihan.

\section{METODE PENELITIAN Sifat Penelitian}

Dalam penelitian ini penulis menggunakan alat penyebaran kuesioner Desain Model Relasional Data Target Costing System, agar tujuan penelitian dapat dicapai lebih akurat. Desain kuesioner yang lebih rinci mengenai suatu isian data selama kurun waktu tertentu dengan cukup mendalam dan menyeluruh yang meliputi berbagai jenis perusahaan di bidang otomotif (mobil), makanan dan minuman, elektronik, peralatan rumah tangga maupun barang konsumen yang ada di Indonesia.

\section{Desain Kuesioner Sistem Informasi Pemetaan Riset Akuntansi}

Database atau biasa juga disebut Basis Data adalah kumpulan data yang berhubungan dengan suatu obyek, yste atau tujuan khusus tertentu. Sebagai contoh buku telepon, kamus bahasa, katalog buku di perpustakaan, data koleksi yste dan video, data pelanggan, data pemasok, data mahasiswa, data pegawai, dan lain-lain.

\section{Pembuatan Desain Kuesioner, dengan Microsoft access 2010 \\ Pembuatan Tabel}

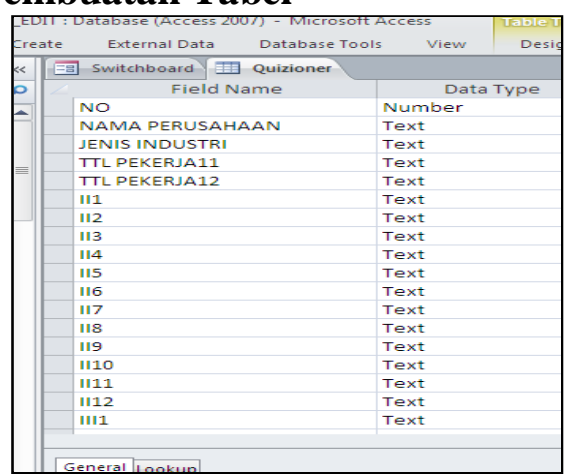

Gambar 2. Pembuatan Tabel Kuesioner

\section{Membuat Menu Utama / Swithboard}

Langkah-langkah pembuatan Menu

\section{Utama}

Tools -> Database Utilities -> Switcboard Manager $\rightarrow$ Yes $\rightarrow$ Edit $\rightarrow$ Ketik Target Costing -> New -> ketik nama menu I. Data Perusahaan $\rightarrow$ Command $\rightarrow$ pilih Open from edit mode $\rightarrow$ Form $\rightarrow$ sesuai dengan urutan menu utama (Switchboard) $>$ kembali ke New untuk penulisan selanjutnya, kemudian klik close (selesai).

\section{Langkah membuat Switchboard}

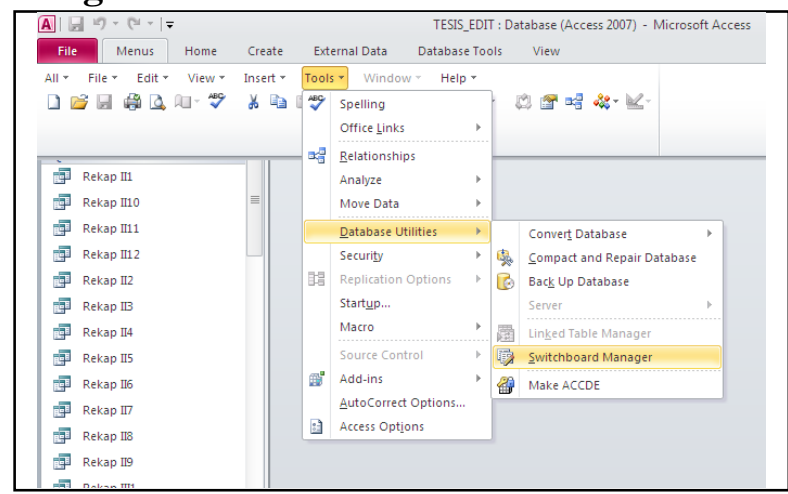

Gambar 3. Desain Switchboard I

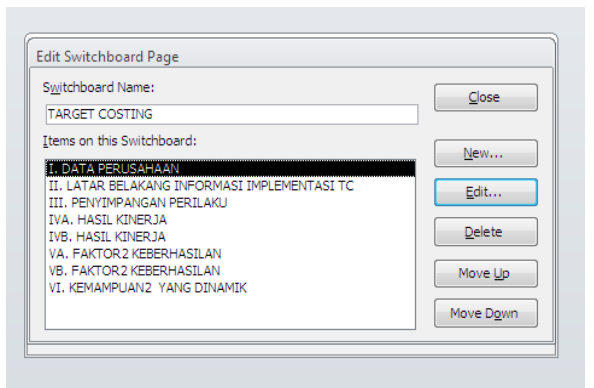

Gambar 4. Desain Switchboard II

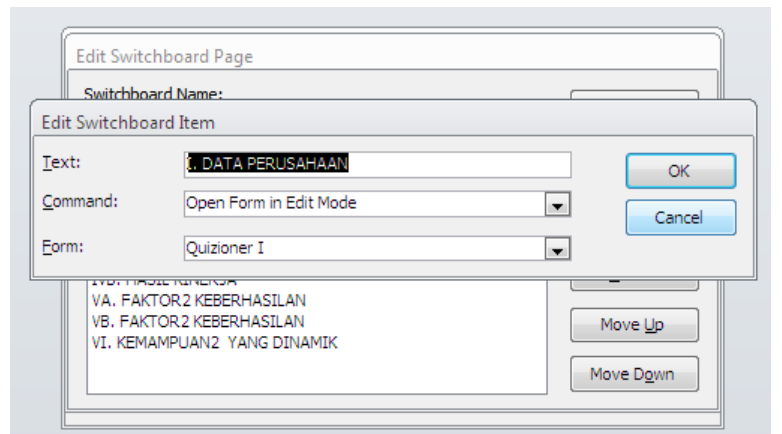

Gambar 5. Desain Switchboard III 


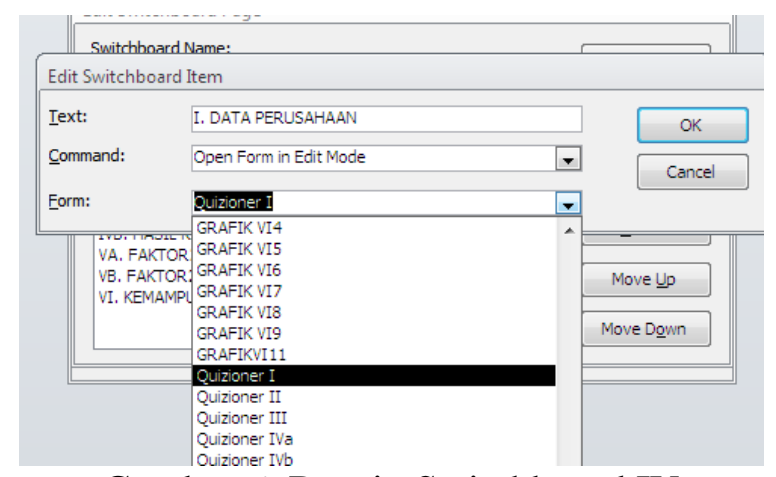

Gambar 6. Desain Switchboard IV

\section{Menu I. Data Perusahaan s/d VI.} Kemampuan-Kemampuan Dinamik

Langkah-langkah pembuatan tampilan Quisioner1 s/d QuisionerVI:

- Create -> Form Wizart -> kemudian table quisioner dipindah ke selected field sesuai dengan urutan di buku quisioner yang terdiri dari No, Nama Perusahaan, Jenis Indutri dst, -> Next -> Columnar $->$ Modify the form's design $>$ Finish

Langkah membuat combo box pada sub quisionerI s/d VI.

- View -> Design -> Label -> di tarik ke form quisioner1 di Detail -> kemudian digeser ke kanan untuk menulis kalimat per item di dalam form quisioner1.

- Kemudian untuk seting pilihan Ya / Tidak sesuai dengan nomor urutan quisioner, klik II1 $\rightarrow$ Properties -> Property Sheet $\rightarrow$ Data $\rightarrow$ Pilih Row Source Type -> Values List -> Row Source $\rightarrow$ Klik $: . .-$ keluar tampilan Edit List Items $\rightarrow$ di isikan sesuai dengan macam-macam pilihan di dalam combo box.

\section{Desain Menu Grafik dan Rekap}

Langkah - Langkah pembuatan tampilan menu grafik dan rekap

Desain Grafik

- Design $\rightarrow$ xoox $\rightarrow$ di tarik $\rightarrow$ klik from operation (grafik) -> open from $\rightarrow$ next $\rightarrow$ pilih II2 (struktur field database quisioner) -> klik next $3 \mathrm{x}$ $>$ kemudian finish.

Desain rekap
- Design $\rightarrow$ coox $\rightarrow$ di tarik $\rightarrow>$ klik miscellius (rekap) $->$ run query $->$ next $\rightarrow>$ next $\rightarrow>$ rekap2 (struktur field database quisioner) -> klik next $3 \mathrm{x}$ $>$ kemudian finish.

\section{Desain Hasil Report Grafik \& Rekapitulasi}

Langkah - langkah pembuatan Report Grafik dan Rekapitulasi

- Report Grafik

Create -> Report Design -> Design -> Chart sorot ke Page Header (Report1) -> Klik Queries -> Next -> Back -> Query: Rekap II1, kemudian ada pilihan Available Field -> II1 \& countOf II1 -> Move ke Fields of Chart $\rightarrow>$ next $\rightarrow$ Pilih Grafik 3-D Pie Chart -> Next -> Finish, save dengan nama file Rekap1

- Report Rekapitulasi

Klik Rekap1 -> klik kanan -> Design view $\rightarrow$ Design $\rightarrow$ Klik Subform /Subreport -> klik, kemudian pindahkan ke Page Header (Rekap1) -> Klik Subreport Wizart $\rightarrow$ Next Tables/Queries -> Pilih Query:Rekap II1 $\rightarrow$ pilih struktur database quisioner \& CountOfII6 $\rightarrow$ Move ke selected fields $->$ Next $->$ Finish

\section{Penyempurnaan Angka Numeric di field Access}

- Sumber data Excel isian Total Pekerja Tahun 2011 dan 2012 data tersebut diterjemahkan database access : < 100, $100-500,500-$ $1000,>1000$.

- Sumber data Excel isian lama penggunaan Target Costing dalam sekian tahun, data tersebut diterjemahkan ke database access : < $5,5-10,10-15,>15$

- Sumber data Excel isian jumlah pekerja Target Costing yang mempunyai wewenang data tersebut diterjemahkan ke database access : < $10,10-50,50-100,>100$ 
PEMBAHASAN

Pengembangan Desain Program Quisioner Target Costing

Langkah pertama adalah membuka program microsoft access seluruh file yang dibutuhkan. Langkah - langkah yang dapat diambil adalah sebagai berikut :

\section{Shortcut | Target Costing}

1. Menu Utama

Menu Utama terdiri dari Data Perusahaan, Latar Belakang Informasi TC, Penyimpangan Perilaku, Hasil Kinerja, Faktor-Faktor keberhasilan, Kemampuan-Kemampuan Dinamik, Grafik \& Rekap.

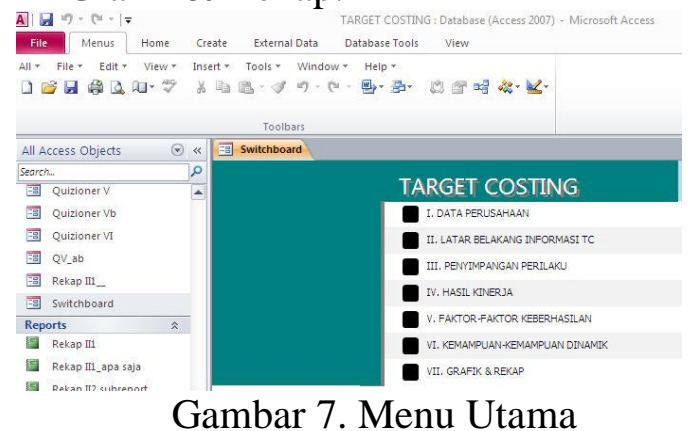

Pada gambar 4.1 menggambarkan suatu tampilan judul dan menu-menu lainnya yang tertera dalam suatu tampilan gambar di atas.

2. Menu Tabel Database Quisioner mengacu pada buku panduan kuesioner Target Costing.

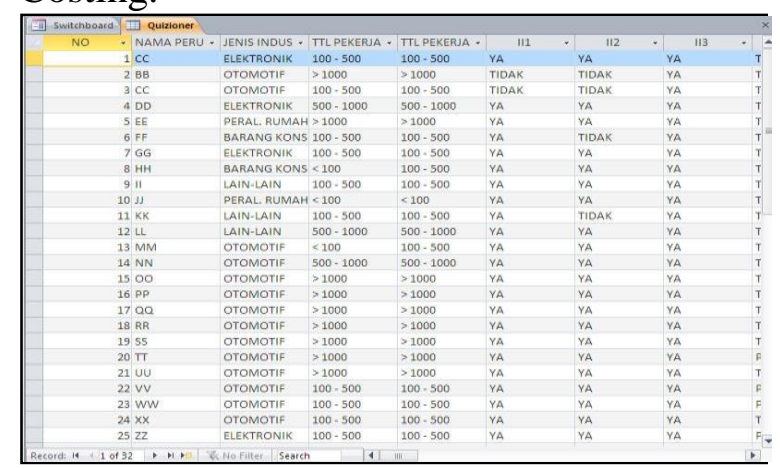

Gambar 8. Data Responden Kuesioner

3. Menu Data Perusahaan

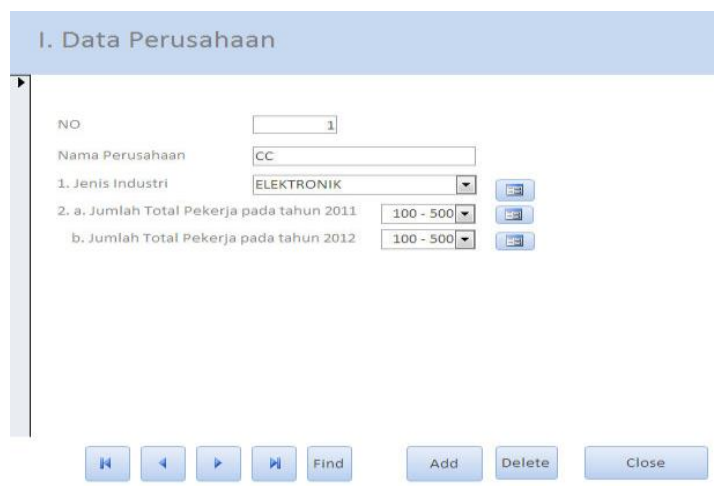

Gambar 9. Isian Data Perusahaan

4. Isian Jenis Industri yang terdiri dari Otomotif, Elektronik, Peralatan Rumah Tangga, Barang Konsumen dan Lainlain

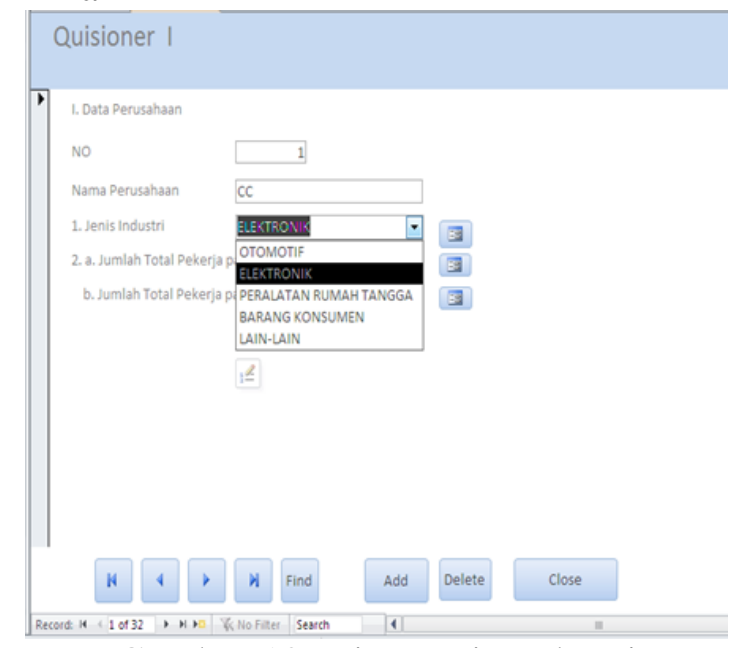

Gambar 10. Isian Jenis Industri

5. Isian Total jumlah pekerja tahun 2011 \& 2012

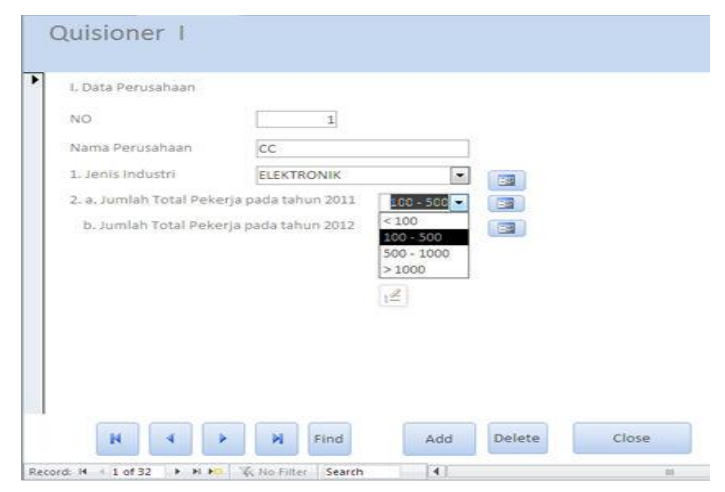

Gambar 11. Isian total pekerja 2011 \& 2012

6. Menu Latar Belakang Informasi Implementasi Target Costing 


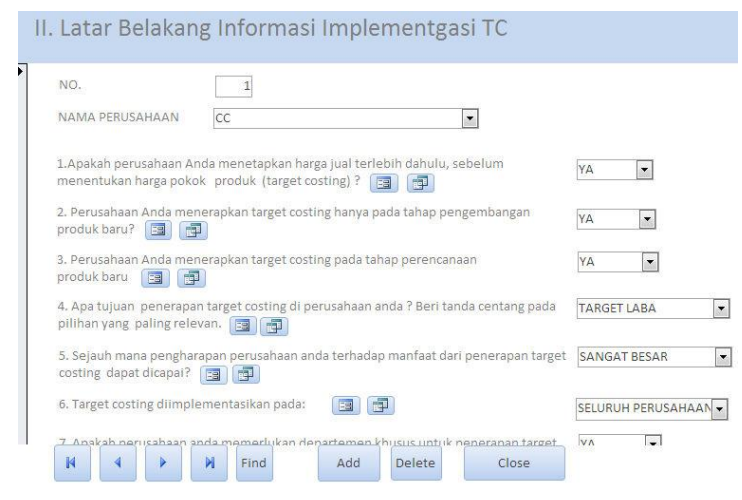

Gambar 12. Isian Latar Belakang TC

7. Menu Penyimpangan Perilaku

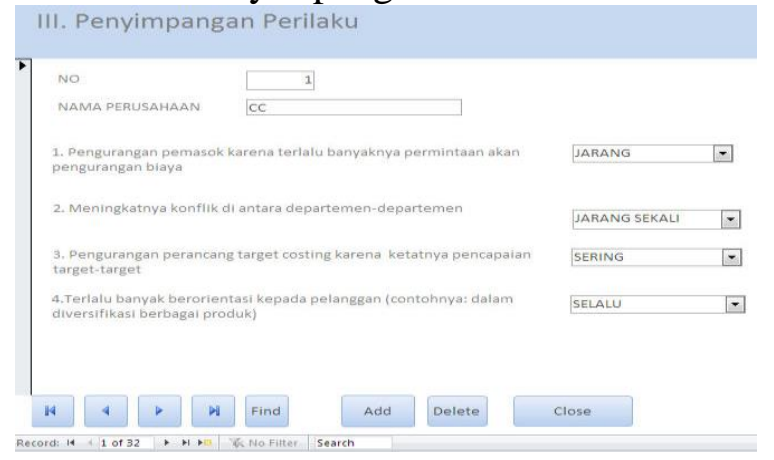

Gambar 13. Isian Penyimpangan Perilaku

Hasil Kinerja

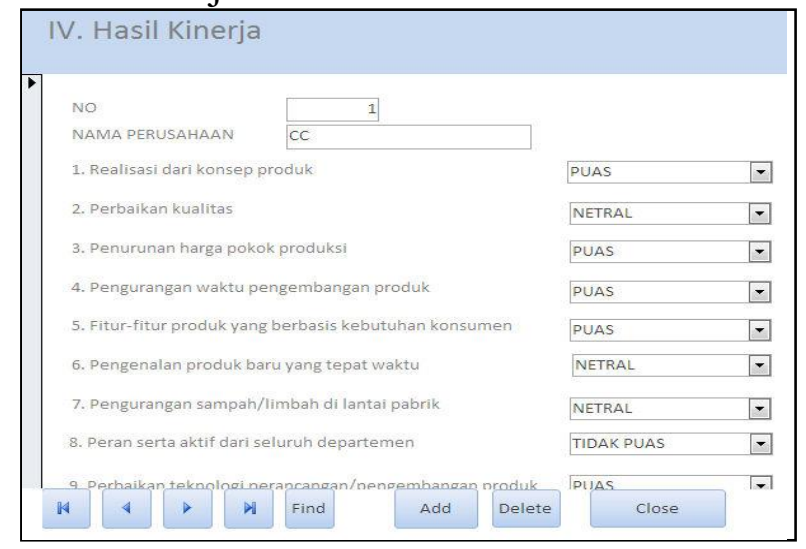

Gambar 14. Hasil Kinerja
8. Faktor - Faktor Keberhasilan

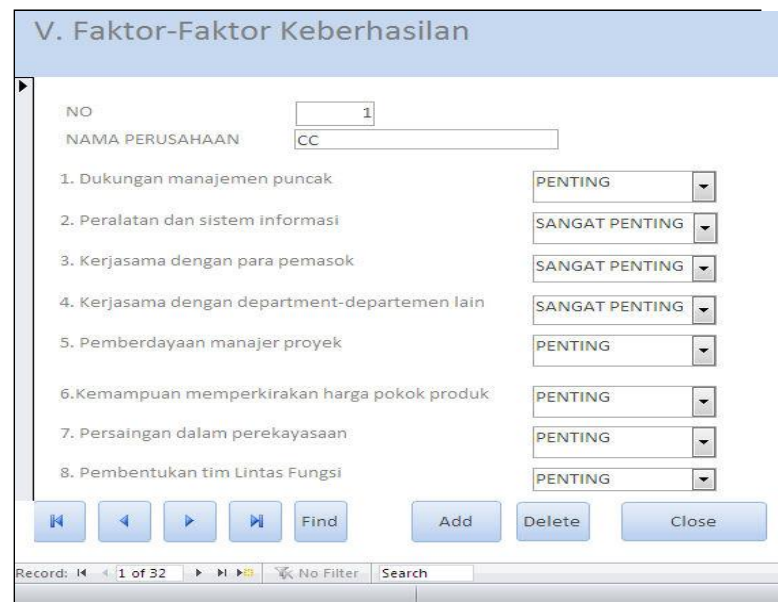

Gambar 15. Faktor-Faktor Keberhasilan

9. Kemampuan - Kemampuan yang Dinamik

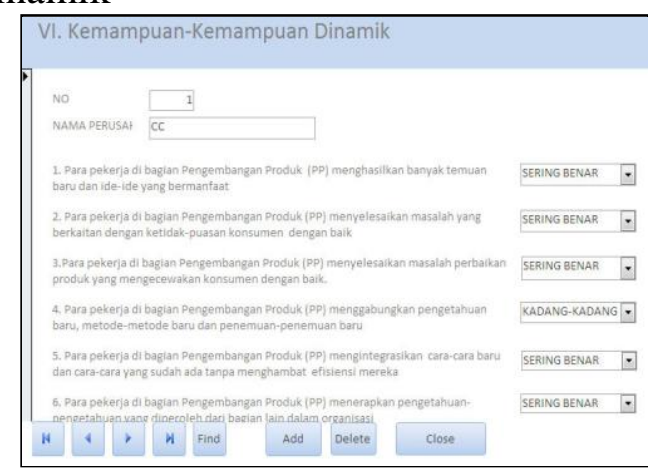

Gambar 16. Kemampuan-Kemampuan Dinamik

10. Grafik \& Rekap

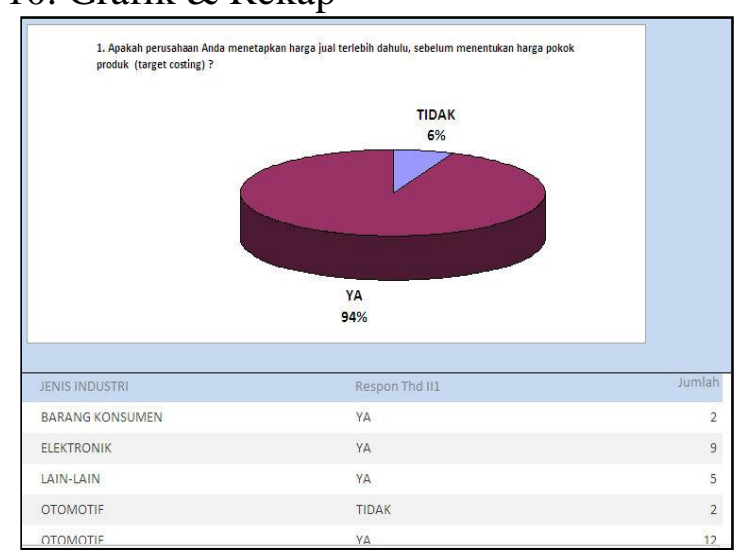

Gambar 17. Hasil Output Grafik dan Rekap

\section{KESIMPULAN DAN SARAN}

\section{Kesimpulan}

Dalam perancangan desain kuesioner Target Costing terhadap sistem yang dibangun maka dapat diambil suatu kesimpulan sebagai berikut : 
1. Kuesioner Target Costing yang telah di desain bermanfaat untuk memberikan suatu sistem informasi yang bisa menghasilkan keluaran (output) maupun input (entri, edit, inquiry, add record), berdasarkan query yang di input sesuai dengan kebutuhan peneliti yang diperlukan terkait dengan target costing.

2. Program Access sebagai alat untuk mendesain, membuat table, membuat form dan membuat laporan

3. Untuk menampilkan hasil yang akurat, maka dengan merancang kuesioner Target Costing, dapat menampilkan data data yang menghasilkan grafik, report, query maupun menyaring data dengan Filter By Form untuk mempermudah dalam pencarian data sesuai dengan kebutuhan peneliti.

\section{SARAN}

Dengan selesainya pembuatan program Desain Target Costing, dari beberapa kesimpulan yang diambil diatas, dapat dikemukakan saran-saran program yang telah kami desain masih banyak kekurangan-kekurangan sehingga dalam pengembangan pembuatan software tersebut masih perlu ditingkatkan lagi perbaikanperbaikan untuk melengkapi software.

\section{DAFTAR PUSTAKA}

Agung H. Marlissa. 2002. Pemrograman Database Mahir Berbasis Access 2002. Cetakan Juni 2005, Indah Surabaya.

Azhar, Kasim. 2005. Teori Pembuatan Keputusan. Jakarta : Fakultas Ekonomi Universitas Indonesia.

Daniel L. Slatnick, Even M Butterfuield. 2005. Computer Application. D.C. Heat and Company.

Fitzgerald, Jerry \& Arda F. Fitzgerald, Warren D. Stalling, Jr. 2001. Fundamentals of System Analysis. New York : John Willey \& Sons

Gordon B. Davis dan Margareth H. Olson. 2004. Management Information
System. Second Edition. McGrag-Hill Book Company.

Iqbal, M. Hasan, 2004. Pokok-Pokok Materi Teori Pengambilan Keputusan. Jakarta : Ghalia Indonesia

Kristanto, Andri, 2003, Perancangan Sistem Informasi dan Aplikasinya, cetakan Pertama, Gava Media, Yogyakarta

Laudon, Kenneth C. 2000." Management Information System". New Jersey: Prentice Hall.

MADCOMS, 2008. Microsof Access 2007 untuk pemula. Edisi I Andi, Yogyakarta

Teguh, Muhammad. 2000. Metode Penelitian Ekonomi, Teori dan Aplikasi. Jakarta Rajawali Press.

Turban, Efraim dan Jaye Aronson. 2005. Decision Support System and Intelligent System(Sistem Pendukung Keputusan dan System Cerdas, Jilid 1. Yogyakarta: Andi.

Whitten, Jeffery L., Bentley, Lonnie D., dan Dittman, Kevin C., 2004, Metode Desain dan Analisis Sistem, Edisi Enam, Mc Graw Hill-Andi, Yogyakarta. 